\title{
LA (DE)CONSTRUGGIÓN DEL SIGNIFICADO EXPRESIVO A PARTIR DE LA MÚSICA POPULAR EN LA PELÍCULA DUCK SOUP (1933) DE LOS HERMANOS MARX
}

\author{
Ramón Sanjuán Mínguez \\ Universidad Politécnica de Valencia
}

\begin{abstract}
\end{abstract}
A pesar de que ha transcurrido más de medio siglo desde que los hermanos Marx filmaron su última película, su obra fílmica ha estado presente durante todos estos años en reposiciones televisivas, ciclos cinematográficos e incluso en homenajes realizados por instituciones tan prestigiosas como el MoMa de Nueva York. De forma paralela, el cine de los Marx ha sido objeto de rigurosos estudios (Louvish, Gehring, Arce, Mitchell y Gardner, entre muchos otros) que han analizado, desde diversas perspectivas artísticas y sociológicas, la vida y la obra de estos cómicos irreverentes. Sin embargo, ninguna de estas investigaciones ha indagado sobre las funciones expresivas desempeñadas por la música popular en sus películas.

En este sentido, nuestro trabajo pretende mostrar un ejemplo concreto del papel decisivo que asumió la música popular en la configuración del significado expresivo del cine de los hermanos Marx. Debido a las restricciones propias de este artículo, nos limitaremos a analizar, a modo de ejemplo, una de las secuencias finales de Sopa de ganso (Duck Soup, 1933), una escena en la que estas músicas populares están muy presentes y condicionan el discurso fílmico, tal y como vamos a intentar demostrar a continuación

\section{EL CINE Y LAS MÚSICAS DE LOS HERMANOS MARX}

Tras iniciar su carrera en diversos grupos vocales, los hermanos Marx comenzaron una irregular pero ascendente trayectoria artística en los circuitos de vaudeville que, con el tiempo, les llevaría a debutar en Broadway en 1924 con la comedia musical I'll Say She Is. En los siguientes años estrenarían dos nuevas obras, The Cocoanuts (1925) y Animal Crackers (1928), cuyo éxito propiciaría sendas adaptaciones fílmicas de estas comedias musicales (en 1929 y 1930, respectivamente) que supondrían su debut cinematográfico. 
En esos años, el crack bursátil de 1929 provocaría una crisis sin precedentes en el mundo del espectáculo de la costa Este y muchos artistas emigrarían a Hollywood, esperando encontrar en el cine un sustento para esos tiempos difíciles (Wecter, 1948: 261). Los Marx no fueron una excepción y en 1930 firmaron un contrato para realizar tres películas con la Paramount: Monkey Business (1931), Horse Feathers (1932) y Duck Soup (1933). A pesar de que su mayor éxito cinematográfico no llegaría hasta A Night at the Opera (1935), producida por la Metro Goldwyn Mayer, las tres películas filmadas con la Paramount están mucho más cerca, en cuanto a concepción y contenido, de los números cómico-musicales que los Marx habían puesto en escena durante sus años en el vaudeville. En este sentido, el primer cine de los hermanos Marx es el único medio sonoro del que disponemos para valorar las funciones que podía desempeñar la música, así como su carácter o procedencia, en los espectáculos de vaudeville que presentaron los Marx antes de convertirse en artistas cinematográficos. De hecho, algunas fuentes de la época, como la publicación Los Angeles Times, confirman una cierta continuidad en los espectáculos de los Marx cuando les recriminan su falta de originalidad, aduciendo que "no pueden hacerse los mismos trucos una y otra vez" (citado en Kanfer, 2000: 287).

Por otra parte, a pesar de que tradicionalmente se ha considerado que la música de cine se conformó a partir de la tradición culta centroeuropea, el contenido musical del primer cine de los Marx nos revela una constante presencia de ciertos elementos musicales populares provenientes de la tradición del vaudeville, así como de los últimos éxitos de la industria de canciones del Tin Pan Alley, lo cual configura una realidad sonora que contradice esa supuesta herencia europea.

\section{SINOPSIS}

La acción de Duck Soup, dirigida por Leo McCarey, transcurre en Freedonia, un país imaginario cuyo gobierno se muestra incapaz de hacer frente a la crisis económica y al malestar ciudadano. En un último y desesperado intento, que recuerda al argumento de Die Lustige Witwe, la opereta de Franz Léhar, los mandatarios solicitan la ayuda económica de Mrs. Teasdale, una adinerada viuda interpretada por Margaret Dumont. Mrs. Teasdale sólo se muestra dispuesta a colaborar en el rescate financiero del país a condición de que se nombre como jefe de estado a Rufus T. Firefly, el personaje encarnado por Groucho Marx. De esta forma, Firefly se hace con el control del país y comienza a gobernarlo de una forma dictatorial, despótica y caprichosa, algo muy acorde con la realidad política de esos años.

Por otra parte, Trentino (Louis Calhern), el embajador de la vecina Sylvania, se siente también atraído por la fortuna de la viuda y pretende casarse con ella para conseguir solucionar así los también acuciantes problemas de su país. Firefly considera a Trentino un temible adversario y ambos se enzarzan en una discusión inútil que culmina con una declaración de guerra entre los dos estados. A pesar de lo dramático de la situación, todo el pueblo de Freedonia celebra el inicio de la guerra con un gran número musical, no exento de un ferviente patriotismo mostrado a través de elementos culturales populares identitarios, entre los que destaca la música. Tras ese número multitudinario, la acción se traslada a los días previos al comienzo de la Guerra de Independencia norteamericana con el fin de parodiar un acontecimiento histórico que va a ser protagonizado por Harpo Marx. Y es precisamente en la música de esta parodia en la que vamos a centrar nuestra atención durante el presente trabajo. 


\section{LAS MÚSICAS DE HARPO-REVERE}

La escena comienza con los cuatro hermanos Marx, vestidos de uniforme, en una posición estática a modo de tableau vivant, un número muy apreciado incluso desde los espectáculos anteriores al vaudeville (Graves, 2000: 37). Harpo, el único de los hermanos que aparece montado a caballo, está caracterizado como Paul Revere, un personaje clave en el comienzo de la Guerra de Independencia norteamericana (1775-1783) (Mitchell, 2006: 100). Revere, orfebre de profesión, ya había participado en 1773 en el llamado Motín del Té, acaecido en Boston, y durante la guerra desempeñaría una labor fundamental transmitiendo mensajes del ejército norteamericano. Precisamente, la acción que nos ocupa transcurrió durante la noche del 18 de abril de 1775, cuando Revere realizó una cabalgada nocturna para advertir a los habitantes de Concord (Massachussets) de la llegada de los soldados británicos, hecho que daría lugar al comienzo la Guerra de la Independencia (Foresman). Es precisamente este acontecimiento, inmortalizado en un poema de Henry W. Longfellow (Longfellos), el que van a parodiar los Marx, utilizando en su mayor parte músicas de corte popular que en esos años gozaban de un cierto éxito'.

\section{UNA CABALLERÍA LIGERA}

La primera obra musical que escuchamos pertenece, sin embargo, a la tradición europea. Harpo-Revere comienza su cabalgada al ritmo de la Obertura de Caballería ligera, la opereta escrita por el compositor austrohúngaro Franz von Suppé, que había sido estrenada en Viena en 1866. La música de Suppé, presentada de forma extradiegética, mantiene una estrecha relación con la narración fílmica por cuanto la 'caballería ligera' era un cuerpo del ejército cuyas misiones se caracterizaban por su velocidad de asalto y no por la fuerza bruta. Además, el ritmo de la música [Figura 1] otorga un gran dinamismo a las imágenes a la vez que se identifica simbólicamente a nivel sonoro con el trote del caballo de Harpo. De esta forma, la música de Caballería Ligera otorga un cierto realismo a la misión patriótica de Harpo-Revere que se presenta inicialmente, pues, desde una perspectiva dramática seria.

\section{AIN'T SHE SWEET?}

No obstante, los Marx no tardan en parodiar los hechos históricos, una costumbre que era habitual en los programas de vaudeville y también en los espectáculos burlesque (Cullen, 2006: 160). Así, Harpo olvida por completo su cometido cuando contempla a través de una

1 A lo largo de presente artículo utilizaremos el concepto de "música popular" para referirnos a un corpus musical que presenta una serie de características concretas que permiten diferenciarlo de la llamada música culta de tradición europea, así como de otras manifestaciones musicales como el folclore o las de carácter étnico, entre otras. En primer lugar, según define Philip Tagg, la música popular "está concebida para una distribución masiva" destinada a grupos de oyentes grandes y socioculturalmente heterogéneos. Por otra parte, esta música se "almacena y distribuye de una forma no escrita". Además, la música popular "sólo es posible en una economía industrial monetaria en la cual se convierte en un artículo de consumo". Por último, este corpus musical está sujeto, a las leyes de libre mercado de la sociedad capitalista según las cuales lo ideal es vender, al mayor número posible de personas, la mayor cantidad posible de una gama limitada de producto. En cualquier caso la "música popular" es también una forma de interpretar y de asimilar culturalmente este corpus musical, construido a partir de las aportaciones de los diversos grupos étnicos y sociales que conformaron Norteamérica a partir de la segunda mitad del siglo XVIII (TAGG, 2001: 4). 


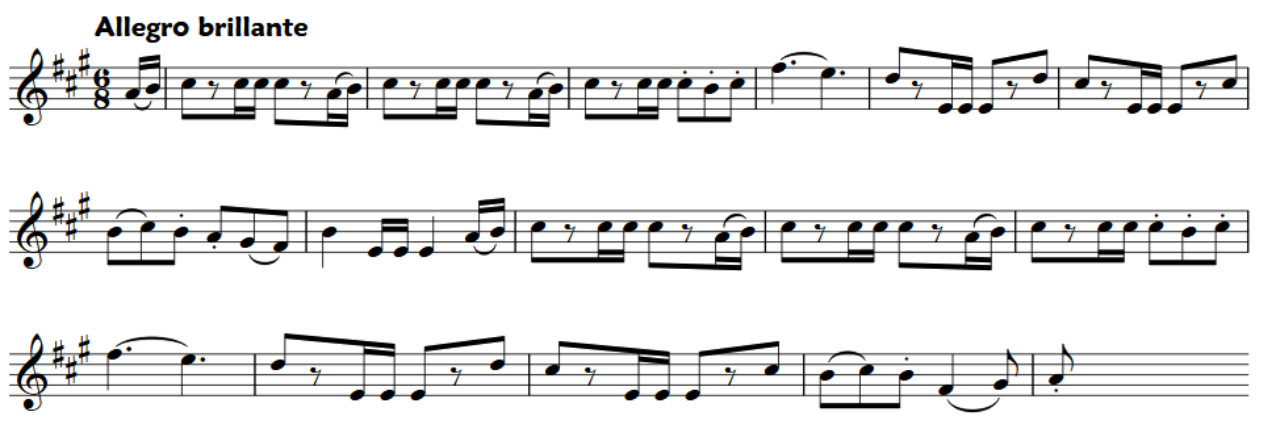

[Figura 1]. Comienzo de la Obertura de Caballería Ligera (Suppé, 1866).

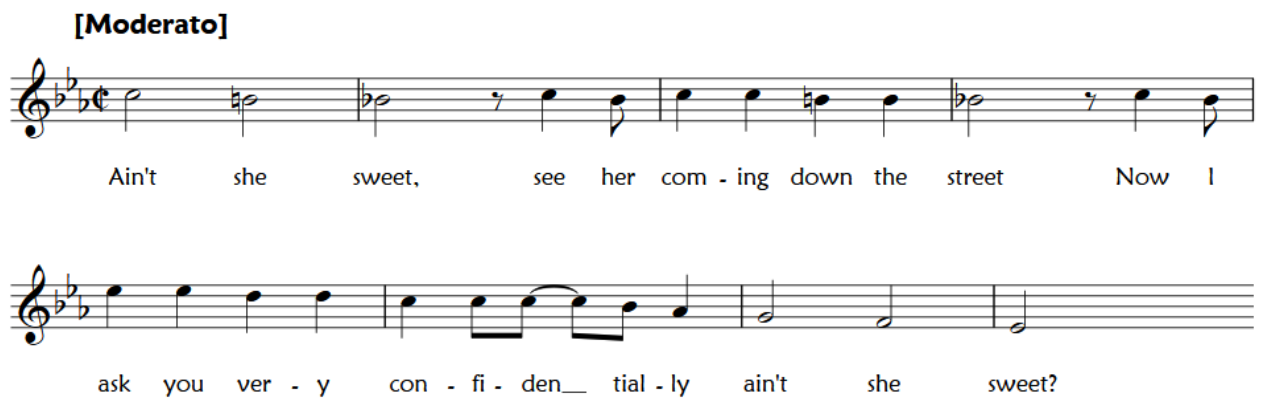

[Figura 2]. Comienzo del estribillo de Ain't She Sweet? (Yellen, 1927).

ventana a una hermosa joven que se está desnudando para darse un baño en un apartamento en el que todos los elementos resultan anacrónicos con respecto a la acción descrita. En ese momento, la música de Suppé ralentiza el tempo de forma análoga a cómo el caballo de Harpo detiene su paso. Es entonces cuando comienza a sonar una nueva melodía, asociada a la mujer que vemos a través de la ventana, y el contenido paródico se impone al tratamiento realista con el que había comenzado la secuencia. En esta ocasión se trata del estribillo de Ain't She Sweet?, una canción escrita por Jack Yellen y Milton Ager en 1927 [Figura 2].

Según Hischak, Ain't She Sweet?, escrita a modo de charlestón, es una de esas canciones despreocupadas de ingenuo amor ñoño que reflejaba la era de la frivolidad y que se había popularizado gracias a los nightclubs y a los teatros de vaudeville (Hischak, 2002: 7). La letra describe la admiración que profesa un joven hacia una atractiva mujer que ha visto caminando por la calle, así como el aturdimiento que siente hacia ella y que le impide comer y conciliar el sueño por las noches. De esta forma, la admiración instantánea que siente Harpo hacia la desconocida joven no está muy lejos, como tampoco lo está su comportamiento, del contenido del texto de la canción de Yellen y Ager².

Sin embargo, la técnica de relacionar la letra de una canción con unas imágenes alusivas a la misma no fue un invento de los hermanos Marx, sino que tiene su antecedente en las llamadas "diapositivas ilustradas", una práctica creada durante los años de vaudeville (Harris, 1907: 5-6). Este número, muy apreciado por el público, consistía en proyectar sobre una pantalla unas fotografías, producidas a tal efecto, que recreaban el texto de la canción que estaba siendo interpretada en directo sobre el escenario (Altman, 2004: 182).

En sus primeras películas, los hermanos Marx utilizaron de forma frecuente esta técnica no sólo para rememorar una tradición artística, sino sobre todo para conseguir burlar el restrictivo

2 Se puede consultar la letra completa de esta canción en: Akers, 2011. 
código Hays, redactado en 1930, a partir de la complicidad de unos espectadores que conocían de antemano las letras de las canciones que utilizaban instrumentalmente en sus películas. De esta forma, aunque el código moral prohibía los bailes que sugerían o representaban acciones sexuales o que enfatizaban movimientos eróticos o indecentes (Bynum, 2006), no parecía existir ningún problema en incluir melodías instrumentales pertenecientes a canciones populares que originalmente estaban escritas o se bailaban con esos ritmos. Así, aunque en la versión de Ain't She Sweet que escuchamos en Duck Soup el ritmo de charlestón está suavizado hasta casi pasar desapercibido, la referencia a este baile, y a la letra de la canción, resultaba evidente para aquellos espectadores que apenas unos años antes habían bailado o escuchado esta obra. En este sentido, el significado expresivo que la música ofrece al conjunto de la escena permite insinuar una sexualidad latente que las imágenes no podían mostrar.

Por otra parte, en esta ocasión también hay un claro intento de sincronizar el ritmo fílmico con el tempo de la música, lo cual permite una mayor interacción de todos los elementos expresivos. De forma equivalente a como la obertura de Caballería ligera se detenía de forma gradual a la vez que el caballo de Harpo, Ain't She Sweet se acelera cuando nuestro protagonista comienza a subir las escaleras, de forma apresurada, para encontrarse con la joven y aliviar así sus deseos carnales.

\section{GOOD NIGHT SWEETHEART}

Pero Ain't She Sweet no es la única melodía que podemos escuchar durante esta escena. En un determinado momento la música se interrumpe y es reemplazada por el estribillo de otra canción mucho más ingenua y que aparentemente no contiene ninguna connotación erótica. En esta ocasión se trata de Good Night Sweetheart [Figura 3], una canción escrita en 1931 por Noble, Campbell y Connelly con un tranquilo ritmo de foxtrot que, según Hischak, «se solía interpretar cómo el último número de los bailes» (Hischak, 2002: 123).

La popularidad de Good Night Sweetheart en esos años queda fuera de toda duda porque se había presentado al público mediante una grabación fonográfica de Rudy Valle, e incluso había sido incorporada a un show de Broadway titulado Earl Carroll's Vanities of 1931 (Hischak, 2002: 123). Aunque en un primer momento la ingenua letra de Good Night Sweetheart no parece guardar ninguna relación con la evidente atracción sexual que siente Harpo hacia la joven que ha encontrado, una lectura más atenta de la secuencia nos permitirá concretar su verdadero significado. Tal y como ya hemos indicado, esta obra nos presenta las hermosas palabras con las que dos amantes se despiden, dándose las buenas noches antes de separarse para irse a dormir. En realidad, el momento preciso en el que comienza a sonar Good Night Sweetheart nos revela quién es la verdadera destinataria de esa música. Harpo, antes de presentarse ante

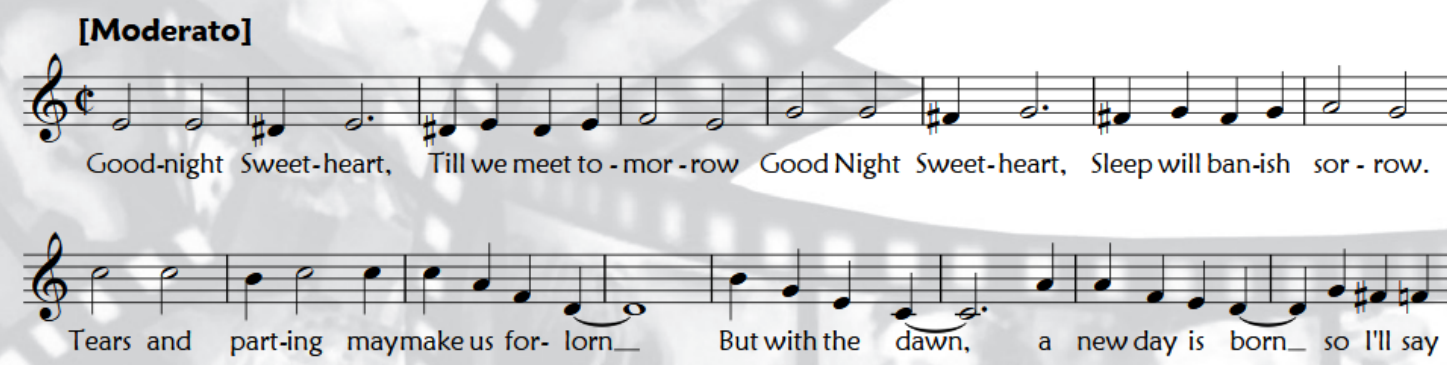

[Figura 3]. Comienzo del estribillo de Good Night Sweetheart (Noble, 1931). 
la joven, sale del edificio a toda prisa, mientras ella se desviste, como si hubiese recapacitado y quisiera marcharse a cumplir su misión. Sin embargo, como vemos a continuación, lo único que pretende es dar de comer a su yegua antes de regresar a la vivienda para pasar la noche con la chica. Así, Harpo-Revere le coloca a su animal una bolsa con forraje para que coma durante la noche y no se sienta abandonada mientras él está con su amante ocasional. Es decir, gracias a la música sabemos que Harpo está dándole las "buenas noches" a su yegua, preocupándose de que no le falte de nada, como si su verdadera intención fuese no despertar sus celos. En este sentido, la letra de Good Night Sweetheart ridiculiza la situación planteada a nivel narrativo en el film, subvirtiendo parte de su significado. De hecho, el código Hays no hubiese permitido mostrar esta infidelidad de Harpo de una forma tan abierta si, en lugar de una yegua, su verdadero amor hubiese sido otra persona (Bynum, 2006) [Figuras 4 y 5].

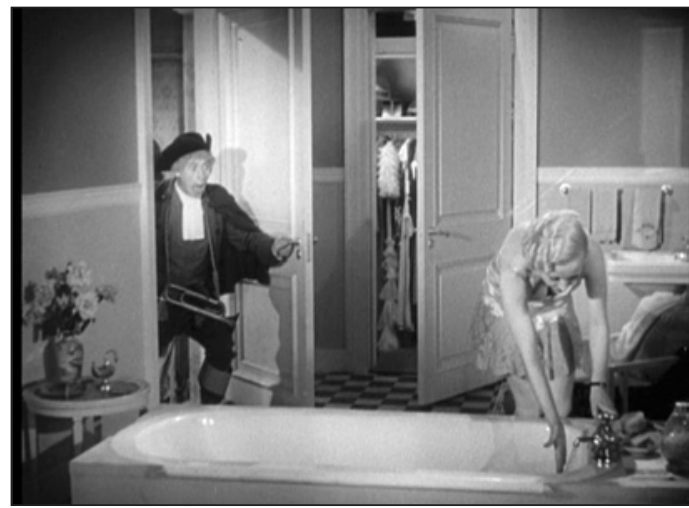

[Figura 4]. Harpo ante su amante ocasional (McCarey, 2003: 56.58").

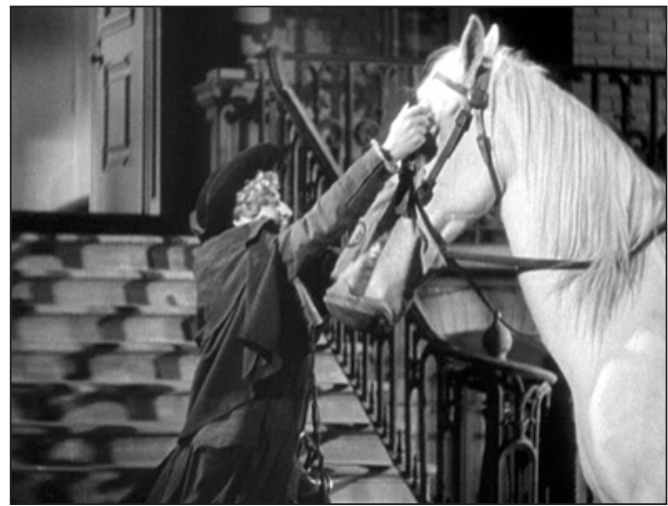

[Figura 5]. Harpo se despide de su amada (McCarey, 2003: 57.05").

En cualquier caso, la precisión con la que se acompaña esta secuencia a nivel musical denota un uso muy preciso del material musical, unas canciones que mantienen siempre una estrecha relación significativa entre el argumento fílmico y el contenido narrativo de su letra. En este sentido, si Ain't She Sweet nos revelaba la irrefrenable atracción sexual que Harpo sentía por la joven, Good Night Sweetheart nos confirma que esa atracción es sólo pasajera y que el verdadero amor de nuestro protagonista es su yegua.

Finalmente, como no podía ser de otra forma, las imágenes no nos llegan a mostrar si Harpo ha consumado o no su deseo carnal y la llegada del marido de la joven precipita la huida de nuestro protagonista.

\section{ONE HOUR WITH YOU}

Harpo-Revere escapa de forma apresurada de la vivienda, acompañado por una breve música orquestal extradiegética, y reemprende su misión patriótica. Acto seguido se aproxima a un viejo caserón en cuya ventana aparece otra joven que le saluda de una forma muy afectuosa, como si le estuviera esperando. Definitivamente, la misión patriótica vuelve a un segundo plano y ahora Harpo sólo parece interesado en las jóvenes que va encontrando a su paso. Justo en ese momento comienza a sonar de forma instrumental el estribillo de One Hour With You, una canción escrita por Richard A. Whiting y Oscar Strauss [Figura 6].

One Hour With You pertenecía a una comedia musical cinematográfica del mismo título que había sido estrenada en 1932, protagonizada por Maurice Chevalier y Jeanette Mac- 


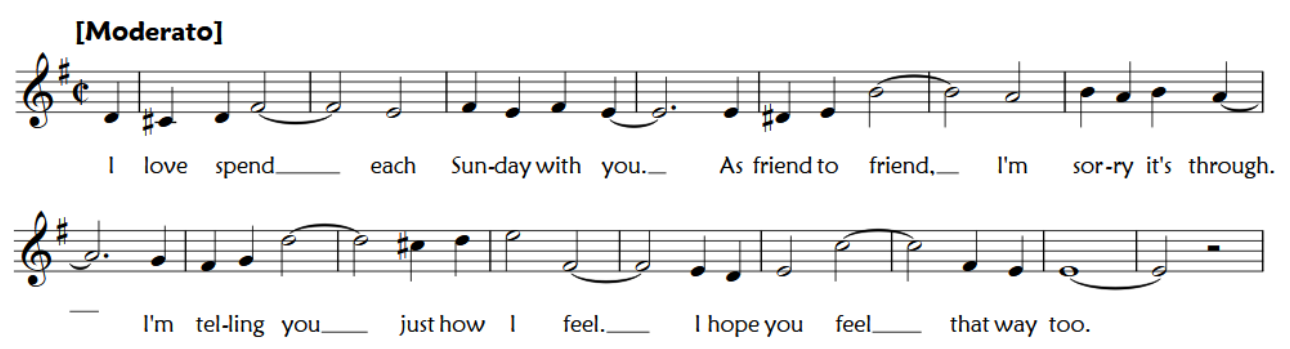

[Figura 6]. Estribillo de One Hour With You (Whiting, 1932).

Donald. Algunos autores señalan que esta obra es tanto una celebración del amor conyugal como un estudio de lo frágil que es la lealtad amorosa (Rich, 2008). En este sentido, no es casual que tanto la fidelidad matrimonial como la atracción por las jóvenes casadas sean dos temáticas muy presentes en la cabalgada de Harpo-Revere. Sin embargo, el desenlace final de esta escena nos presenta esa lealtad desde un punto de vista completamente inesperado.

\section{THE OLD GRAY MARE}

Harpo entra en la vivienda, dispuesto a satisfacer sus deseos carnales. De hecho, en un primer momento, comprendemos que se ha desnudado y que está en la cama con la joven que tan amorosamente le ha recibido. $O$ al menos eso es lo que se deduce cuando vemos en el suelo, justo al lado de la cama, las botas de Harpo-Revere y los zapatos de su nueva amante ocasional en un plano corto, presentado mediante un travelling lateral [Figura 7]. Pero este movimiento de cámara sólo se detiene cuando, de forma inesperada, nos muestra al lado de los zapatos de la joven las cuatro herraduras de su yegua [Figura 8].

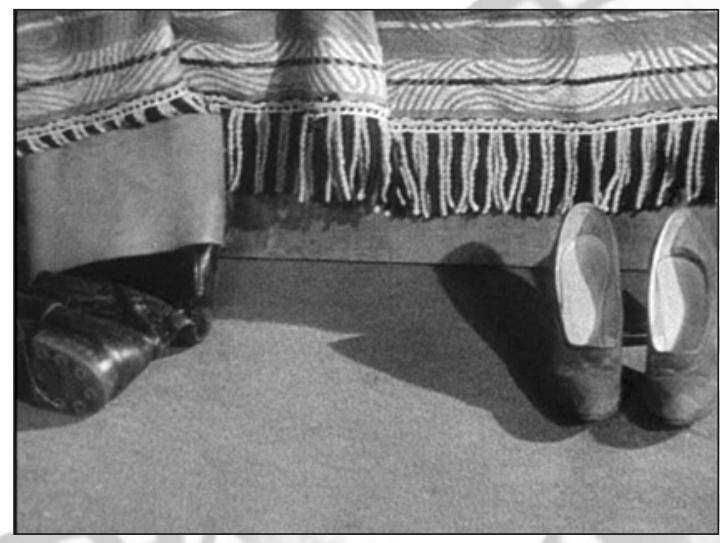

[Figura 7]. Las botas de Harpo y los zapatos de la joven (McCarey, 2003: 58.14").

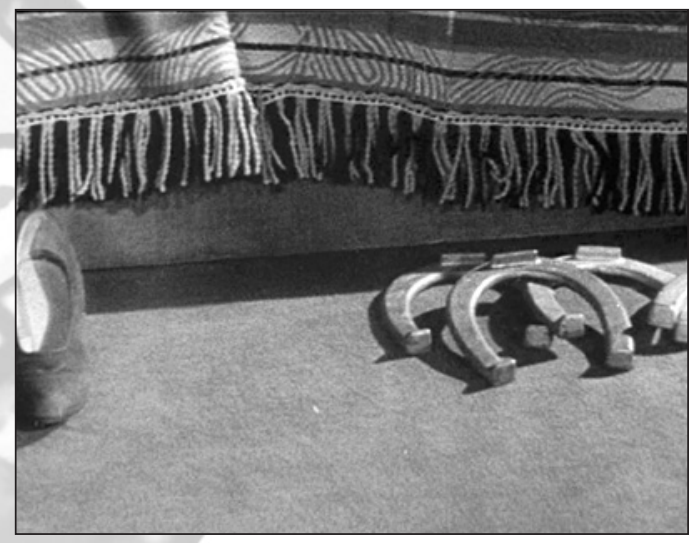

[Figura 8]. Las herraduras de la yegua (McCarey, 2003: 58.18").

El siguiente plano nos presenta un desenlace completamente sorprendente. Harpo está durmiendo con su yegua, mientras que en la cama de al lado la joven descansa sin nadie que la acompañe [Figura 9].

Aunque este típico desenlace wow, propio del Harpo más vaudevillesque, puede responder a un intento de burlar la censura, lo cierto es que también permite establecer otro tipo de significados. El código Hays no permitía visualizar a nuestro protagonista compartiendo cama con una amante ocasional, ni tampoco autorizaba a presentar escenas de desnudo (Bynum, 2006). Sin embargo, no existe ninguna prohibición contraria a mostrar las herraduras de un cuadrúpedo 


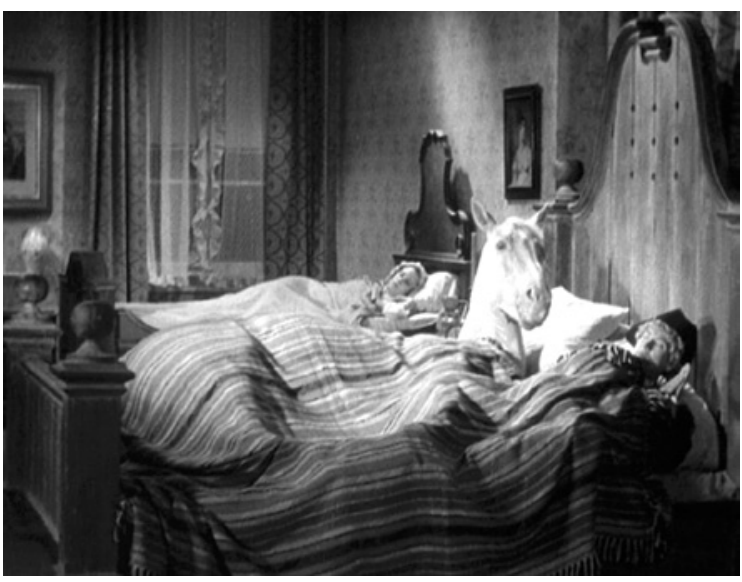

[Figura 9]. Harpo comparte el lecho con su yegua (McCarey, 2003: 58.23"). al lado de la cama, ni tampoco una imagen en la que una yegua comparta lecho con su dueño. En este sentido, los Marx no sólo están ridiculizando de este modo el famoso código moral, sino que, además, subvierten esta escena amorosa hasta el límite de lo absurdo, gracias a una nueva cita musical. Así, justo en el momento en el que la cámara nos muestra los zapatos de la joven, una nueva melodía comienza a sonar, cuyo significado suponemos que no podía pasar desapercibido para la gran mayoría del público norteamericano. Se trata de la canción tradicional titulada The Old Gray Mare ("La vieja yegua gris") [Figura 10].

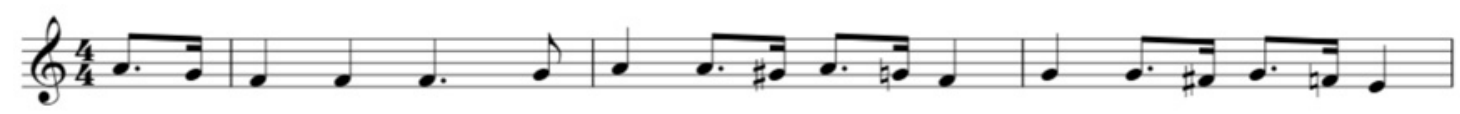

Oh the old gray mare, she ain't what sheused to be, Ain't what sheused to be,

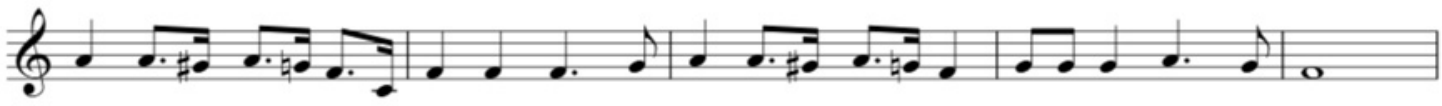

Ain't what she used to be the old gray mare, She ain't what she used to be, man-y long years a - go.

[Figura 10]. The Old Gray Mare ("The Old Gray Mare", 2004).

Si relacionamos la letra de The Old Gray Mare con las imágenes que hemos descrito, encontraremos el verdadero significado que los Marx quieren otorgar a esta secuencia. Así, la interacción de la ingenua letra de esta canción tradicional con las imágenes que vemos nos aporta un significado sexual del cual adolece la canción original. Si asumimos que Harpo está durmiendo con su yegua, después de haber tenido un posible encuentro sexual con ella, y recordamos la letra de esta canción el significado de la escena parece obvio: «la vieja yegua gris no es lo que solía ser muchos años atrás». Es decir, las imágenes que vemos manipulan el sentido original de la canción, revelándonos ahora que Harpo no ha quedado del todo satisfecho con su encuentro sexual zoofílico. Aún así, resulta evidente que Harpo prefiere el amor de su yegua antes que a la joven que duerme en la cama de al lado. De esta forma, mediante la utilización de las canciones populares, los Marx consiguen burlar el restrictivo código Hays, insinuando mediante la música lo que apenas unos años antes se mostraba de forma abierta y desinhibida y que ahora ni siquiera se podía sugerir visual o textualmente.

Finalmente, la misión de Harpo concluye con un fundido a negro que da paso a la escena bélica con la que finaliza la película. Es decir, Harpo-Revere duerme con su yegua en la casa de su amante y, por lo tanto, no ha llegado a completar la misión que le habían encomendado. Así, esta ausencia de un desenlace narrativo, más propia de un final marxiano wow vaudevillesque que de un argumento realista cinematográfico, manifiesta la prevalencia de una estética teatral encaminada más hacia la consecución de unos sorprendentes giros cómicos puntuales que hacia la cohesión narrativa. Paradójicamente, el auténtico Paul Revere tampoco llegó nunca a consumar su misión porque «fue capturado por los británicos antes de llegar a Concord» (Foresman). 


\section{CONCLUSIONES}

Aunque la música de tradición centroeuropea está presente a nivel anecdótico en la secuencia analizada, es la música popular la que se muestra como la verdadera protagonista del film. Su presencia no sólo es constante durante toda la escena comentada, sino que, además, es ella la que articula y cohesiona el discurso narrativo, así como el significado final de las secuencias en las cuales se inscribe.

A partir de la técnica de las "canciones ilustradas", procedente del sustrato cultural del vaudeville, los Marx parodian los estribillos de los éxitos musicales populares de su tiempo al incluirlos en escenas fílmicas cuya narración presenta una relación muy estrecha con el contenido del texto de la canción. El gran cuidado y precisión con el que los Marx abordan esta tarea demuestra que no se trata de una coincidencia casual o de un recurso improvisado durante la edición del film, sino que es algo inherente a la propia construcción del guión, y también una práctica con la que los hermanos Marx estaban muy familiarizados.

Por otra parte, la utilización instrumental del estribillo de estas canciones les permite, en complicidad con los espectadores que conocían las letras, burlar el restrictivo código moral instaurado por la Hays Office a comienzos de los años treinta, insinuando así unos contenidos abiertamente sexuales ausentes en el cine de su tiempo.

En definitiva, resulta imprescindible conocer las canciones populares que los Marx utilizan en su cine para comprender el significado último de las secuencias en las cuales se inscriben. De esta forma, la música popular se revela como un elemento decisivo en la construcción del significado expresivo o paródico del cine de los hermanos Marx.

Por último, consideramos que es necesario revisar la importancia que tuvieron las músicas populares en la configuración de la música cinematográfica durante los primeros años del cine sonoro. Unas músicas que han sido relegadas sistemáticamente en las investigaciones fílmicas hasta estos últimos años, pero que están muy presentes en las producciones cinematográficas en la primera mitad de los años treinta.

\section{BIBLIOGRAFÍA}

"The Old Gray Mare" 2004. Sheet Music Digital. 2004. URL: http://www.sheetmusicdigital. com/aboutpdffilesyoudownload.asp?ID=DL10000278 [Último acceso: 03/04/2014].

AKERS, Peter (trans.) 2011, YELLEN, Jack y AGER, Milton, "Ain't She Sweet?", International Lyrics Playground. URL: http://lyricsplayground.com/alpha/songs/a/aintshesweet.shtml [Último acceso: 03/04/2014].

ALTMAN, Rick, Silent Film Sound, Nueva York, Columbia UP, 2004.

BYNUM, Matt, "The Motion Picture Production Code of 1930 (Hays Code)", Arts Reformation, 2006. URL: http://www.artsreformation.com/a001/hays-code.html [Último acceso: 06/04/2014].

CULLEN, Frank, Vaudeville, Old and New: An Encyclopedia of Variety Performers in America, Nueva York, Routledge Press, 2006.

FORESMAN, Scott, "Paul Revere", Estudios Sociales. Pearson Education Inc. URL: http:// www.estudiossocialessf.com/bio/revere.html [Último acceso: 06/04/2014].

GRAVES, Nadine George, The Royalty of Negro Vaudeville: The Whitman Sisters and the Negotiation of Race, Gender and Class in African American Theater 1900-1940, Nueva York, St. Martin's Press, 2000. 
HARRIS, Charles, Illustrating Song Slides. Movie Picture World, 9 de marzo de 1907. Págs. 5 y 6. URL: http://hearingthemovies.blogspot.com/search/label/Tin\%20Pan\%20Alley [Último acceso: 06/04/2014].

HISCHAK, Thomas S., The Tin Pan Alley Song Encyclopedia, Westport, Greenwood Press. Connecticut, 2002.

KANFER, Stefan, Groucho, una biografía, Barcelona, RBA, 2000.

LONGFELLOW, Henry Wadsworth: Paul Revere's Ride. The EServer Poetry Collection. URL: http://poetry.eserver.org/paul-revere.html [Último acceso: 05/04/2014].

MITCHELL, Glenn, The Marx Brothers Encyclopedia, Londres, Reynolds \& Hearn Ltd, 2006.

NOBLE, Ray y otros: "Good Night Sweetheart. The Song Favorite of the King and Queen of England". 1931 Jcholarship. URL: https://jscholarship.library.jhu.edu/ handle/1774.2/2307[Último acceso: 04/04/2014].

RICH, Jamie S., "Lubitsch Musicals: One Hour With You - Eclipse Series 8". Criterion Confessions, 2008. URL: http://www.criterionconfessions.com/2008_02_01_archive.html [Último acceso: 03/04/2014].

SUPPÉ, Franz Von, Leichte Kavallerie. Leipzig. August Cranz 1866. Reimpresión: Dover. IMSLP. URL: $\quad$ http://conquest.ims/p.info/files/imglnks/usimg/8/8b/IMSLP18865-PMLP44579Suppe_CavalryOv.pdf [Último acceso: 05/04/2014].

TAGG, Philip, Analysing popular music: theory, method and practice. Pág. 4. 2001. URL: http://www.tagg.org/articles/xpdfs/pm2anal.pdf [Último acceso: 19/12/2013].

WECTER, Dixon, The Age of the Great Depression 1929-1941, New York, Macmillan, 1948. Citado en: JONES, John Bush, Our Musicals, Ourselves. A Social History of the American Musical Theatre, New England, Brandeis UP, 2003.

WHITING, Richard A. y STRAUSS Oscar. "One Hour With You" Music Notes. 1932 URL: http://www.musicnotes.com/sheetmusic/mtdFPE.asp?ppn=MN0018815 [Último acceso: 04/04/2014].

YELLEN, Jack y AGER, Milton. "Ain't She Sweet?" Warner Bross., Online Sheet Music, 1927. URL: http://www.onlinesheetmusic.com/aint-she-sweet-p277980.aspx [Último acceso: 03/04/2014].

\section{REFERENCIAS FÍLMICAS}

McCAREY, Leo (dir.), Duck Soup, Paramount, 1933. (DVD). Edición española: Sopa de Ganso, Madrid, Universal Pictures Iberia, 2003. 